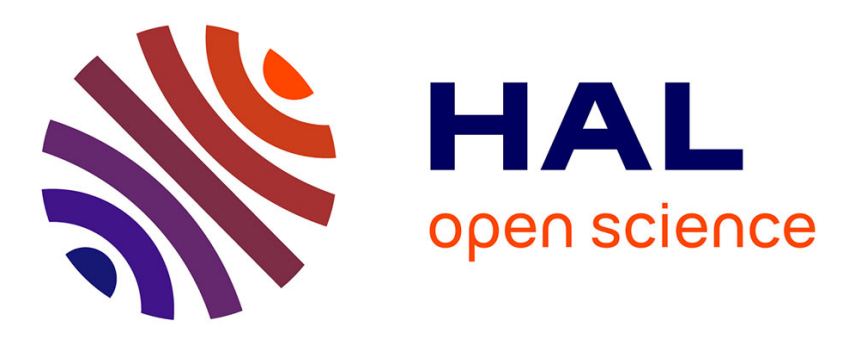

\title{
Influence of operating parameters on the single-pass photocatalytic removal efficiency of acrylonitrile
}

Henrietta Essie Whyte, Cécile Raillard, Albert Subrenat, Valérie Hequet

\section{To cite this version:}

Henrietta Essie Whyte, Cécile Raillard, Albert Subrenat, Valérie Hequet. Influence of operating parameters on the single-pass photocatalytic removal efficiency of acrylonitrile. Journal of Photochemistry and Photobiology A: Chemistry, 2019, 382, pp.111905. 10.1016/j.jphotochem.2019.111905 . hal-02285110

\section{HAL Id: hal-02285110 https://imt-atlantique.hal.science/hal-02285110}

Submitted on 12 Sep 2019

HAL is a multi-disciplinary open access archive for the deposit and dissemination of scientific research documents, whether they are published or not. The documents may come from teaching and research institutions in France or abroad, or from public or private research centers.
L'archive ouverte pluridisciplinaire HAL, est destinée au dépôt et à la diffusion de documents scientifiques de niveau recherche, publiés ou non, émanant des établissements d'enseignement et de recherche français ou étrangers, des laboratoires publics ou privés. 


\title{
Influence of operating parameters on the single-pass photocatalytic removal efficiency of acrylonitrile
}

\author{
Henrietta Essie Whyte*, Cécile Raillard, Albert Subrenat, Valérie Héquet \\ IMT Atlantique, GEPEA UMR CNRS 6144, 4 Rue Alfred Kastler CS 20722, 44307 Nantes Cedex 3, France
}

Keywords:

Indoor air treatment

PCO

Operating rooms

Acrylonitrile

Single-pass removal efficiency

\begin{abstract}
A B S T R A C T
Photocatalytic oxidation (PCO) is an advanced air cleaning technology that is used as a means to improve air quality in indoor environments and could also potentially be used in hospital operating rooms (ORs). However, when it comes to the feasibility of using PCO to remove VOCs, most studies have been on those that are commonly found in indoor environments like homes and schools. There are little or no studies on other indoor environments like hospitals. Therefore in this work, acrylonitrile, one of the hazardous compounds found in surgical smoke (a source of pollution in the OR) was chosen as a representative compound to evaluate the performance of a photocatalytic system in an OR. The experiments were performed in a 420-L multi-pass laboratory reactor. The performance of the system was based on the influence that three operating parameters (air velocity, light intensity and initial concentration) would have on the single-pass removal efficiency (SPRE). A mathematical model was used to enable the calculation of the SPRE from the experimental degradation profile. The influence of the operating parameters on the degradation of acrylonitrile as well as the possible intermediates formed and mineralization rates are discussed.
\end{abstract}

\section{Introduction}

Indoor Air Quality (IAQ) is an important issue in industrialized and developed countries due to the considerable time people spend indoors [1]. In hospitals however, the IAQ is even more critical, because of the increased susceptibility of the patients [2]. Consequently poor IAQ can lead to nosocomial infections and occupational diseases [3,4].

The first concern when it comes to IAQ in the hospital is with microbial contamination because they cause nosocomial infections whilst contamination with chemical pollutants is rarely considered. However, hospital occupants can be exposed to a variety of chemical pollutants due to the diversity of activities that take place in the different zones in the hospital [5-7]. One of the most demanding zones when it comes to IAQ is the operating room (OR). In the OR, the air can be contaminated by waste anesthetic gases, disinfection and sterilization products, surgical smoke and particles like lint, respiratory droplets and aerosols [8-10]. The literature reports that one of the main culprits of air pollution in ORs is surgical smoke [11]. Surgeons and operating theatre staff are routinely exposed to pollution from the surgical smoke. It hinders the vision of the surgeon, produces an unpleasant odor, and releases harmful substances into the air that are harmful to the staff [12]. The chemicals present in greatest quantity in surgical smoke are hydrocarbons and nitrile compounds among which is acrylonitrile
$[10,13,14]$.

Acrylonitrile is a hazardous compound that has been classified as a Group-2B (possibly carcinogenic to humans) carcinogen by the IARC [15]. The occupational exposure limit (OEL) for an 8-h time weighted average set by NIOSH is $2 \mathrm{ppm}$. Short-term exposure to acrylonitrile can cause eye irritation, nausea, vomiting, headache, sneezing, weakness and light headedness, whilst long-term exposure may cause cancer $[16,17]$. There are not a lot of studies that show the concentration levels of acrylonitrile in the OR. Barret and Garber [10] reported acrylonitrile concentrations in ORs to be between 1 and $1.6 \mathrm{ppm}$. Chung et al. [18] measured average acrylonitrile concentration of $15 \mathrm{ppm}$ in a Korean OR.

In ORs, the IAQ is ensured by heating, ventilation and air conditioning (HVAC) systems through the dilution of indoor air pollutant concentrations by the supply of conditioned outdoor air [9]. However this is not always sufficient thus air treatment devices are gaining popularity as complementary methods to ensure good air quality [19-23]. These devices are accepted by The Center for Disease Control and Prevention (CDC) in the US and the Société Française d'Hygiène Hospitalière $(\mathrm{SF} 2 \mathrm{H})$ in France for treating the air and also improving ventilation in ORs [24,25]. These treatment devices are based on processes such as ozonation, cold plasma, UV disinfection and photocatalytic oxidation (PCO) to purify the air.

\footnotetext{
* Corresponding author.

E-mail address: henrietta.whyte@imt-atlantique.fr (H.E. Whyte)
} 


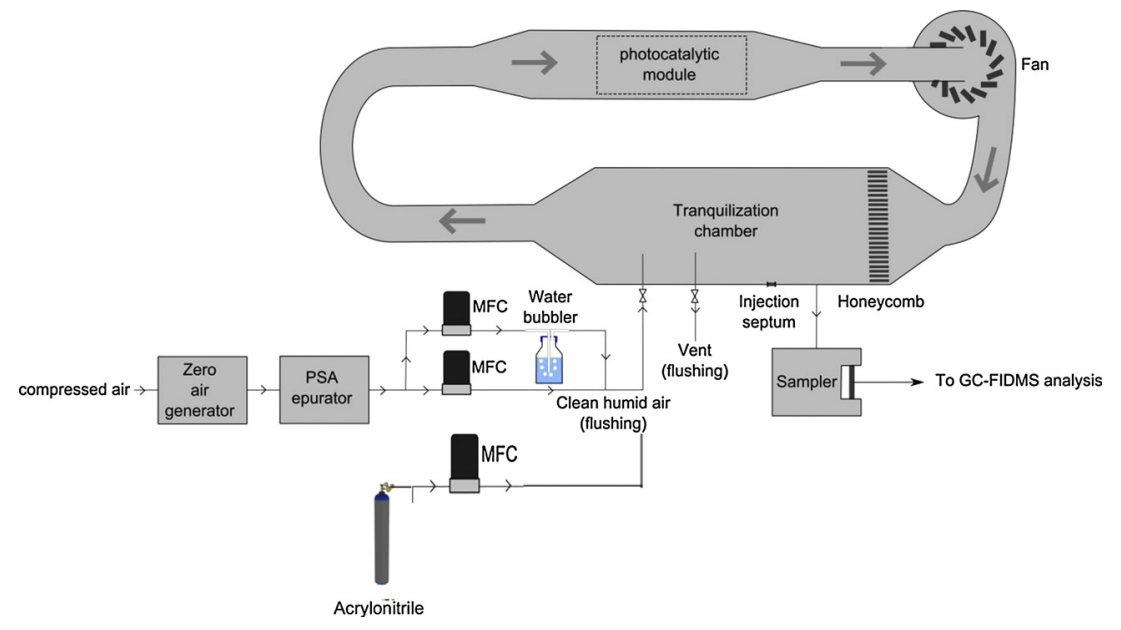

Fig. 1. Schematic representation of the closed-loop photocatalytic reactor.

PCO is an efficient technology that exists for air treatment. It has the advantage of being cheap and a flexible solution for the degradation of a wide spectrum of volatile organic compounds (VOCs) [26-29]. It removes gaseous contaminants via chemical reactions on semiconductor (mostly $\mathrm{TiO}_{2}$ ) catalyst surface under UV irradiation. There has been a lot of work published in the literature on the efficiency of PCO for the removal of several pollutants [30-32]. The influence of several key parameters such as VOC concentration, UV light intensity, air velocity and relative humidity on the degradation of pollutants have also been extensively studied [33-38]. In the literature, the performance of photocatalytic systems is based on the use of descriptors like the kinetic rate constant, the clean air delivery rate, the single-pass removal efficiency and energy efficiency index [39-41].

Most of the focus of PCO studies has been on pollutants that are typically found in homes, schools and offices without much attention being paid to specific pollutants found in other indoor environments like hospitals. Additionally, as PCO devices could be potentially used in the ORs as a complementary means of improving IAQ it is necessary to study the feasibility of PCO for the removal of a typical OR pollutant. The PCO of acrylonitrile has not been widely studied in the literature. Krichevskaya et al. [42] studied the gas phase degradation of acrylonitrile by using Degussa P25 under UV irradiation at concentrations ranging from 10 to $100 \mathrm{ppm}$ at temperatures ranging from 50 to $130^{\circ} \mathrm{C}$. They observed that degradation rates were improved at longer contact times and lower concentrations and decreased at higher temperatures. They also reported that the products of gas-phase acrylonitrile PCO included carbon dioxide, water and nitrogen dioxide and hydrogen cyanide. Joks et al. [43] also studied gas-phase PCO of acrylonitrile on sulphated $\mathrm{TiO}_{2}$ and showed improved performance at higher temperature and longer retention times under UV irradiation. They identified hydrogen cyanide and isocyanic acid as intermediates. Pang et al. [44] in studying suspension phase (the catalyst was suspended in aqueous solution of acrylonitrile) acrylonitrile degradation on F-doped $\mathrm{TiO}_{2}$ / $\mathrm{SiO}_{2}$ catalyst under simulant solar light irradiation reported higher photocatalytic activity for the F- doped samples due to the increase of number and strength of surface acid sites. In another study using N-F codoped $\mathrm{TiO}_{2} / \mathrm{SiO}_{2}$ under simulant solar light irradiation, Pang et al. [45] identified some organic acids (formic acid, acroleic acid, acetic acid) as the intermediates of suspension phase acrylonitrile degradation. These works however were performed at high initial concentrations ( $>10 \mathrm{ppm}$ ) or under conditions not relevant to ORs. Thus, further studies on the efficiency of PCO of acrylonitrile at more realistic OR conditions are necessary.

This work therefore focuses on evaluating the efficiency of PCO of acrylonitrile under conditions that are relevant to actual OR applications with the objective of studying the influence of air velocity, light intensity and initial concentration on the single-pass removal efficiency. The study of the influence of these parameters will help to provide knowledge to improve the efficiency of the system and finally to highlight the performance of PCO in real OR conditions. The influence of initial pollutant concentration on the mineralization rates is also examined. The single-pass removal efficiency (SPRE) is chosen as an indicator because commercial air purification units that are available on the market mostly operate under single-pass configuration in which a volume of air passes through the reactor once for treatment. Thus it would be a representative way to evaluate the performance of a PCO device. The experiments were conducted in a closed loop reactor which has been designed to study low concentration air pollutants and has also been recently modeled $[46,47]$. This reactor also permits a better representation of PCO systems developed in dynamic mode and is realistic regarding air treatment systems working as standalone devices or implanted in HVAC systems.

\section{Materials and methods}

\subsection{Generation of acrylonitrile concentrations}

In order to generate the desired concentrations of the pollutant, gaseous acrylonitrile $\left(\mathrm{C}_{3} \mathrm{H}_{3} \mathrm{~N}\right)$ supplied by Air products was used. It was supplied in a certified commercial gas cylinder at a concentration of $149 \mathrm{ppm}$ and balanced in nitrogen at 150 bars. The generation process was started by first passing compressed air through Claind 2020 air zero generator to clean it. It was then humidified to a desired level by bubbling it through a water bottle at an average room temperature of $20^{\circ} \mathrm{C}$. Prior to injection into the reactor, acrylonitrile was mixed with the humid air zero to dilute it. The desired concentrations of acrylonitrile were achieved by adjusting the gas flow rates using mass flow controllers (Brooks).

\subsection{Photocatalytic reactor}

A 420-L closed-loop reactor operating in recirculating mode was used for the experiments. This reactor is presented in Fig. 1 and has been described in previous articles [48-51]. The air flow through the reactor is controlled by a variable speed which allows a flow rate from 28 to $300 \mathrm{Nm}^{3} \cdot \mathrm{h}^{-1}$. Acrylonitrile is introduced into the reactor through a valve in the tranquilization chamber which is equipped with a honeycomb to enable a homogeneous flow distribution. Sampling is also done from the tranquilization chamber. The photocatalytic module houses the media and the lamps. The media used is QUARTZEL ${ }^{\circledR}$ PCO supplied by Saint-Gobain Quartz. It consists of $\mathrm{SiO}_{2}$ fibers coated with $\mathrm{TiO}_{2}$ deposited through a sol-gel method with average thickness of 
$17.5 \pm 1.5 \mathrm{~mm}$, a developed surface of $0.04 \mathrm{~m}^{2}(20 \mathrm{~cm} \times 20 \mathrm{~cm})$ and a $\mathrm{TiO}_{2}$ load of $94 \mathrm{~g} \cdot \mathrm{m}^{-2}$. The BET specific surface area was measured at $112 \pm 1 \mathrm{~m}^{2} \cdot \mathrm{g}^{-1}$ with a Micrometrics ASAP 2020 by $\mathrm{N}_{2}$ adsorption.

The media was irradiated by two 18 -W UVC $(254 \mathrm{~nm})$ fluorescent tubes (Phillips TUV PL-L series). A Vilber Laurmat VLX-3W radiometer equipped with a calibrated CX-254 nm sensor was used to measure the irradiance over the entire photocatalytic media surface. The average light intensities were achieved by using a variable voltage supply to modify the power of the lamps. Prior to each experimental run, the reactor and photocatalytic media were cleaned by flushing with humid zero air under UV irradiation for several hours. Preliminary experiments were also carried out to evaluate the extent of adsorption process on acrylonitrile removal. The removal rates for adsorption were calculated at $0.1 \%$ per hour indicating that no significant loss of acrylonitrile was observed when exposed to the media without UV light.

\subsection{Operating conditions}

The air velocities varied from 0.5 to $1.5 \mathrm{~m} . \mathrm{s}^{-1}$ and were determined as the ratio between the air flow rate $\left(73-216 \mathrm{Nm}^{3} . \mathrm{h}^{-1}\right)$ and the crosssectional area $\left(0.04 \mathrm{~m}^{2}\right)$ of the photocatalytic module. The selected average light intensities (I) ranged from 1 to $4.5 \mathrm{~mW} . \mathrm{cm}^{-2}$. The ranges of velocity and light intensity were chosen based on the operating conditions typically used by a commercial air purifier that was studied. Initial concentrations $\left(\mathrm{C}_{0}\right)$ chosen for the experiments ranged from 0.5 to $10 \mathrm{ppm}$ and would be representative of the concentration levels that could be found in the OR $[10,18]$. The relative humidity $(\mathrm{RH})$ was maintained at $50 \%$ at $20^{\circ} \mathrm{C}$ to be representative of average humidity levels.

\subsection{Sampling and analytical methods}

The concentrations of acrylonitrile were monitored by sampling onto sorbent tubes packed with Carbopack B (Perkin Elmer). The sampling was done at a rate of $200 \mathrm{ml}^{\mathrm{min}} \mathrm{min}^{-1}$ for $2.5 \mathrm{~min}$, using an Automatic Clean Room Sampling System (ACROSS) by Tera Environnement. The analysis was carried out using a Thermal Desorber/Gas Chromatograph/Flame Ionization Detector/Mass Spectrometer (TD/GC/FID/MS). The column used in the GC was a polar column from Restek (Rxi-624Sil MS) which was connected to a FID for the quantification of compounds and a MS for the identification of compounds. The TD/GC/FID/MS analysis conditions are described in a previous article [51]. The limit of detection for acrylonitrile was calculated as $0.075 \mathrm{ppm}$ for acrylonitrile calculated by multiplying the background noise by 3 . The concentrations of $\mathrm{CO}_{2}$ produced during the degradation were measured with an Ecotech EC $9820 \mathrm{~T}$ infra-red spectrometer.

\subsection{Calculating the single-pass removal efficiency}

As previously mentioned, the reactor used in this work is a multi pass reactor. This reactor is well adapted to provide information on the concentration degradation profiles over the entire duration of the experiment. It however does not provide direct information on the singlepass removal efficiency. This indicator has to be determined indirectly by employing mathematical models. In this work the model that is used has been developed by Dumont and Héquet [46]. In this work, the model that is used is based on one proposed by Walker and Wragg [52] for the concentration-time relationship for a recirculating reactor system and adapted by Dumont and Héquet [46] for the photocatalytic system displayed at Fig. 1. Considering two assumptions, described in details in [46], the equation proposed by Walker and Wragg was simplified. The first assumption stated that as the volume of the photocatalytic module is small in relation to the volume of the reactor, the residence time in the photocatalytic module is small compared to that in the reactor. Thus the concentration-time relationship is given as:
$\mathrm{C}=C_{0} \exp \left(-\frac{t}{\tau_{R}}\left[1-\exp \left(-k \tau_{P}\right)\right]\right)$

In Eq. (1) $\tau_{R}$ is the residence time in the reactor which is the complete closed loop system, $C$ is the pollutant concentration at time $t$ and $C_{O}$ is the initial pollutant concentration, $\tau_{P}$ is the residence time in the photocatalytic module and $k$ is the kinetic constant (which is a composite expression accounting for several chemical kinetics and reactor dynamics mechanisms).

The term $\mathrm{k} \tau_{\mathrm{P}}$ (lumped as $\alpha$ ) is the fractional yield of the treated flow rate of the PCO device. In other words, $\alpha$ is the single-pass removal efficiency and represents the fraction of the total flow treated during the time $\tau_{\mathrm{R}}$. Then, Eq (1) can be rewritten as follows:

$\mathrm{C}=C_{0} \exp \left(-\frac{t}{\tau_{R}}[1-\exp (-\alpha)]\right)$

The second assumption stated that since the volume of the photocatalytic module is small compared to the reactor, the $\alpha$ value is small with regards to the flow rate. In this case, Taylors theorem leads to the approximation that $\alpha \approx \exp (1-\alpha)$. Thus Eq. (2) can be simplified as Eq 3 :

$\mathrm{C}=C_{0} \exp \left(-\frac{t}{\tau_{R}} \alpha\right)$

However, in this study Eq. (2) is used in the determination of $\alpha$. Numerical resolutions were carried out using Excel ${ }^{\oplus}$ Solver which is based on the least- square method.

\section{Results and discussion}

\subsection{Degradation profile of acrylonitrile}

Acrylonitrile degradation profile is shown in Fig. 2. Under the experimental conditions of $\mathrm{C}_{0}=2 \mathrm{ppm}, \mathrm{v}=1 \mathrm{~m} \cdot \mathrm{s}^{-1}$ and $\mathrm{I}=4.5 \mathrm{~mW} \cdot \mathrm{m}^{-2}$ the complete degradation of acrylonitrile was achieved after $1 \mathrm{~h}$ and it was characterized by an exponential profile. The experimental points were then fitted to the model (Eq. 2) and were shown to fit satisfactorily based on the regression co-efficient $\left(\mathrm{R}^{2}\right)$ of 0.99 . Under these conditions, the single-pass removal efficiency $(\alpha)$ was then calculated as 0.012 . This indicated that in one pass, $1.2 \%$ of acrylonitrile would be eliminated from the total flow that passed through the media.

To be able to study the influence of the three operating parameters on $\alpha$ two of the parameters were held constant whilst the third was varied. The reference experiment $\left(\mathrm{C}_{0}=2 \mathrm{ppm}, \mathrm{v}=1 \mathrm{~m} . \mathrm{s}^{-1}\right.$ and $\mathrm{I}$

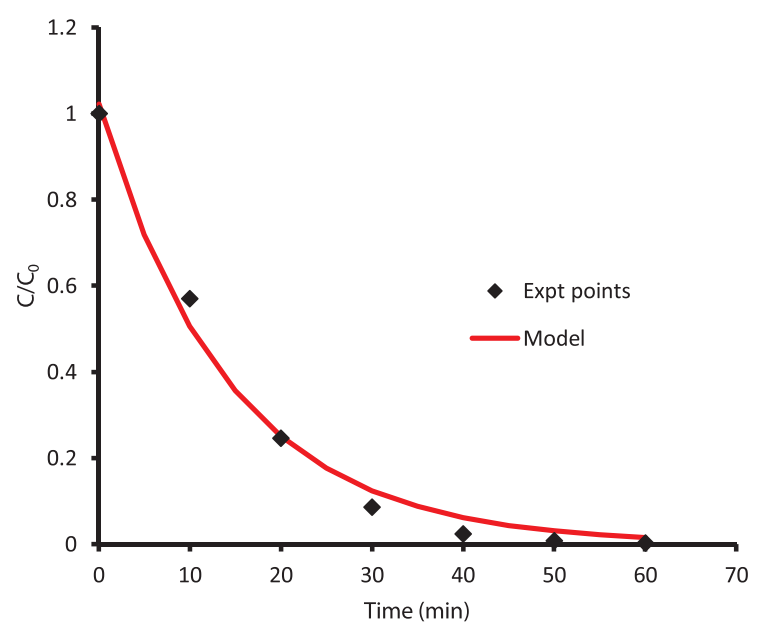

Fig. 2. Experimental degradation curve of acrylonitrile fitted to model developed by Dumont and Héquet under reference experimental conditions of $\mathrm{C}_{0}=$ $2 \mathrm{ppm} ; \mathrm{v}=1 \mathrm{~m} . \mathrm{s}^{-1} ; \mathrm{I}=4.5 \mathrm{~mW} . \mathrm{cm}^{-2}, \mathrm{RH}=50 \%$. 
Table 1

Experimental conditions for PCO degradation of acrylonitrile and experimental results using the Dumont and Héquet [46] model.

\begin{tabular}{|c|c|c|c|c|c|}
\hline \multicolumn{4}{|c|}{ Experimental Conditions } & \multicolumn{2}{|c|}{$\begin{array}{l}\text { SPRE calculation by Dumont and } \\
\text { Héquet model }\end{array}$} \\
\hline Exp & $\mathrm{C}_{0}(\mathrm{ppm})$ & $\mathrm{v}\left(\mathrm{m} \cdot \mathrm{s}^{-1}\right)$ & $\mathrm{I}\left(\mathrm{mW} \cdot \mathrm{cm}^{-2}\right)$ & $\alpha\left(10^{-2}\right)$ & $\mathrm{R}^{2}$ \\
\hline 1 & 2 & 1 & 4.5 & 1.20 & 0.99 \\
\hline 2 & 2 & 1 & 4.5 & 1.22 & 0.99 \\
\hline 3 & 2 & 1 & 4.5 & 1.22 & 0.97 \\
\hline 4 & 2 & 0.5 & 4.5 & 4.07 & 0.99 \\
\hline 5 & 2 & 0.75 & 4.5 & 2.26 & 0.99 \\
\hline 6 & 2 & 1.25 & 4.5 & 0.92 & 0.97 \\
\hline 7 & 2 & 1.5 & 4.5 & 0.75 & 0.98 \\
\hline 8 & 2 & 1 & 1 & 0.52 & 0.99 \\
\hline 9 & 2 & 1 & 2 & 0.68 & 0.99 \\
\hline 10 & 2 & 1 & 3 & 0.82 & 0.99 \\
\hline 11 & 2 & 1 & 4 & 1.04 & 0.99 \\
\hline 12 & 0.5 & 1 & 4.5 & 3.16 & 0.99 \\
\hline 13 & 10 & 1 & 4.5 & 0.66 & 0.99 \\
\hline
\end{tabular}

$=4.5 \mathrm{~mW} \cdot \mathrm{m}^{-2}$ ) was repeated three times and the coefficient of variation of $\alpha$ was calculated as $1 \%$. The results of the analysis of these $13 \mathrm{ex}$ periments are shown in Table 1 . The reference experiment was carried out at regular intervals over the course of the experimental part to make sure that the photocatalyst was not deactivated. The results of the 3 experiments (Table 1 ) were quite similar and indicated that no deactivation occurred during experimental part.

\subsection{Influence of the air velocity on the single-pass removal efficiency during photocatalytic degradation of acrylonitrile}

In this work, the velocity is studied in order to determine the sensitivity of PCO performance to a change in velocity. The experiments were carried out at velocities ranging from 0.5 to $1.5 \mathrm{~m} . \mathrm{s}^{-1}$. This range was chosen based on the operating conditions typically used by commercial air purifiers.

For single-pass reactors, the effect of air velocity is known to present a dual antagonistic effect [53]. As the velocity increases the mass transfer improves but the contact time between the pollutant and the photocatalytic media decreases. Some authors have observed a positive effect of the increase in velocities on the photocatalytic degradation of pollutants due to improvement in mass transfer [54,55] whilst others have observed negative effect of increasing velocities attributed to insufficient contact time [26,56,57]. Depending on the range of velocities studied, a transition between the effects can also be observed. For example, Yang et al. [58] studied the degradation of formaldehyde using a single pass tubular foam-nickel PCO reactor and observed that the removal efficiencies increased when velocities were increased from 0.47 to $0.66 \mathrm{~m} . \mathrm{s}^{-1}$, whilst removal efficiencies decreased when velocities ranged from 0.66 to $0.94 \mathrm{~m} . \mathrm{s}^{-1}$. They explained this by the fact that when velocities were increased from low values $\left(0.47 \mathrm{~m} . \mathrm{s}^{-1}\right)$ there was an enhancement in the mass transfer rate leading to an increase in removal efficiencies. However, once the air velocity reached $0.66 \mathrm{~m} . \mathrm{s}^{-1}$, the removal efficiencies declined due to a reduction in contact time between the pollutants and the photocatalytic media. At this stage, the process was no longer controlled by the mass transfer but by the surface reaction.

The Reynolds number has been described as a good indicator to set an appropriate regime to determine mass transfer limitations. Obee [59] demonstrated when he studied the degradation of $0.7 \mathrm{ppm}$ of toluene in a $\mathrm{TiO}_{2}$-coated glass-plate reactor that with a Reynolds number over 500 the photocatalytic reaction was less influenced by mass transfer. In the present work, the photocatalytic module was inserted in a $20 \mathrm{~cm} \times 20 \mathrm{~cm}$ square cross-section so that the hydraulic diameter was $20 \mathrm{~cm}$. The Reynolds number thus ranged between 6500 and 19,800 , depending on the air velocity value ( 0.5 to $1.5 \mathrm{~m} . \mathrm{s}^{-1}$ ). This

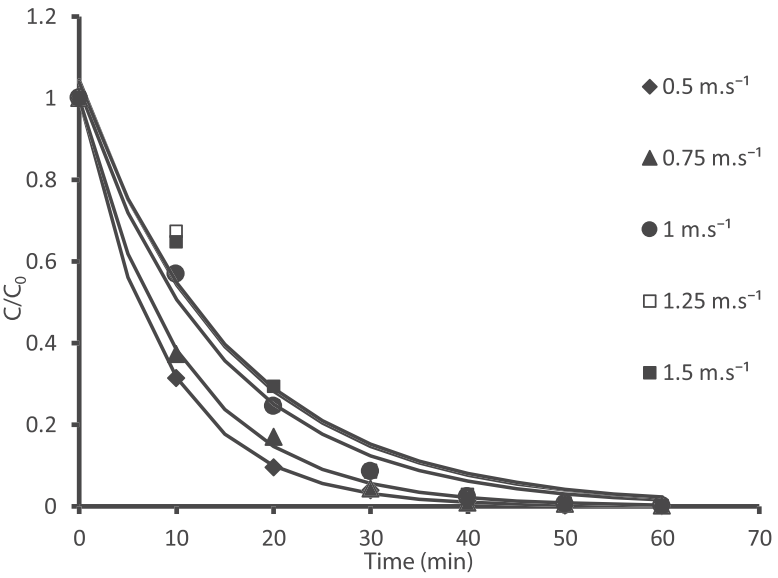

Fig. 3. Degradation curves of acrylonitrile velocity experiments fitted to model to obtain $\alpha\left(C_{O}=2 \mathrm{ppm} ; I=4.5 \mathrm{~mW} . \mathrm{cm}^{-2}\right.$; $\left.\mathrm{RH}=50 \%\right)$.

means that the mass transfer is not a limiting factor.

In multi-pass reactors, the velocity brings into play an additional effect which is the number of passes of the pollutant through the media. Therefore, when the velocity within the media is increased, the contact time decreases but then the number of passes of the pollutant through the media increases. The superposition of these two effects subsequently makes it difficult to highlight the influence of velocity on the reaction rate. Consequently, the global effect of the velocity on the degradation remains the same irrespective of the velocity. In studying the degradation of toluene in a multi-pass reactor, Batault et al. [48] observed that the velocity had no influence on the kinetic constant due to the superposition of the contact time and number of passes.

In this study however, the air velocity was shown to have an influence on the entire kinetic curve of acrylonitrile even though operating in a multi-pass system as shown in Fig. 3.

An assumption is made that there is competition created between the velocity of the molecules through the media and the amount of time needed for molecules to react with active species created by the media. Thus, increasing the velocity tends to not favor the occurrence of the chemical reaction. This would in turn emphasize the influence of air velocity on the kinetic degradation. In order to clearly bring into evidence the influence of the velocity on the degradation of acrylonitrile, the single-pass removal efficiency is chosen as the descriptor. The results obtained for acrylonitrile experiments are discussed below.

The initial concentration, $\mathrm{C}_{0}$ and light intensity, I were maintained at $2 \mathrm{ppm}$ and $4.5 \mathrm{~mW} . \mathrm{cm}^{-2}$ respectively. The results of the experiments are shown in Fig. 4.

It can be observed that as the velocity increases from 0.5 to $1.5 \mathrm{~m} . \mathrm{s}^{-1}$, the $\alpha$ decreases from 0.04 to 0.007 . This is in accordance

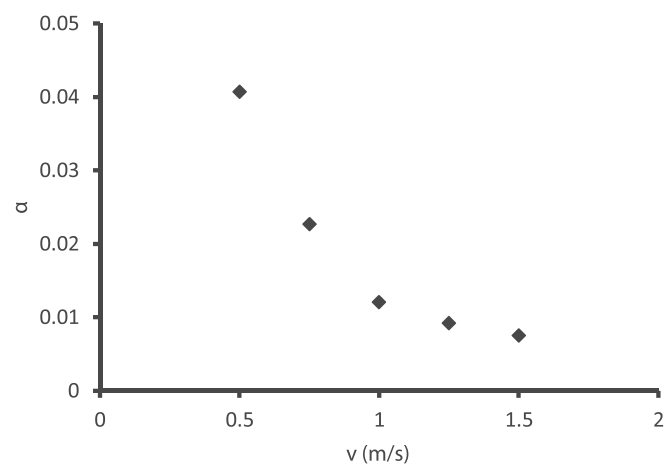

Fig. 4. Influence of air velocity on the single-pass photocatalytic removal efficiency of acrylonitrile under experimental conditions of $\mathrm{C}_{0}=2 \mathrm{ppm}$; I $=4.5 \mathrm{~mW} . \mathrm{cm}^{-2} ; \mathrm{RH}=50 \%$. 
with what some authors observed in the literature. Zhong et al. [57] studied the degradation of 8 VOCs (ethanol, 1-butanol, hexane, octane, acetone, MEK, toluene and p-xylene) at $0.5 \mathrm{ppm}$ in a single-pass reactor. They observed that when the velocities were increased from 0.12 to $0.76 \mathrm{~m} . \mathrm{s}^{-1}$, the removal efficiencies of all of the compounds decreased. Similarly, Ginestet et al. [60] found that the single-pass removal efficiencies of ethanol, toluene and acetone decreased in half when airflow rate increased from $40 \mathrm{~m}^{3} \cdot \mathrm{h}^{-1}$ to $80 \mathrm{~m}^{3} \cdot \mathrm{h}^{-1}$. These authors attributed the decrease in single-pass removal efficiencies to insufficient contact time. In this work, as the velocity is increased, the residence time of acrylonitrile molecules within the media is decreased consequently leading to shorter contact time between the molecules and the photocatalytic media which then leads to a decrease in the removal efficiencies.

The study of the influence of velocity on the degradation of acrylonitrile showed that increasing the contact time between the molecules and the photocatalytic media is an important factor in improving the efficiency of the degradation system. Consequently, it can be said that, to be able to improve the effectiveness of removal, high single pass removal efficiencies are needed which can be achieved at lower velocities.

\subsection{Influence of the light intensity on the single-pass removal efficiency during photocatalytic degradation of acrylonitrile}

During PCO, the light intensity plays a crucial role on the degradation of pollutants as UV light generates photons that activate the photocatalyst to create the electron-hole pairs that will in turn lead to the photocatalytic oxidation of the pollutants [30]. In photocatalysis, the influence of light intensity varies as a power function, $\mathrm{I}^{\mathrm{n}}$ where $\mathrm{n}$ approaches 1 at very low intensities and approaches 0 at very high intensities. According to what is commonly agreed in the literature, depending on the range of light intensities studied, the order " $n$ " can transition into 3 regimes [61,62]. At low light intensity, the production of electron-hole pairs is low and so they are rapidly consumed by the chemical reactions resulting in a linear increase in the reaction rate $(n=1)$. At medium-high light intensity, rate of formation of electronhole pairs is higher than their consumption leading to recombination of the charges resulting half order increase in the reaction rate $(n=0.5)$. At very high light intensity, the electron-hole recombination is so fast that the degradation efficiency no longer depends on the light intensity and reaches a plateau $(n=0)$. Lim and Kim [63] who studied the degradation of trichloroethylene, reported a transition of regimes from first order to half-order when light intensities were increased from 0.25 to $9 \mathrm{~mW} \cdot \mathrm{cm}^{-2}$. They observed that when the light intensity increased from 0.25 to $2 \mathrm{~mW} . \mathrm{cm}^{-2}$, the degradation efficiency of TCE increased linearly $(n=1)$ due to the rapid consumption of the electron hole pairs. When the light intensity was increased from 2 to $9 \mathrm{~mW} . \mathrm{cm}^{-2}$, the degradation efficiency followed a half order regime $(n=0.5)$ which they attributed to faster electron-hole recombination. It should be mentioned that an increment in the light intensity leads to higher degradation rate; however excessive light intensity diminishes the quantum efficiency due to electron-hole recombination. When electronhole pairs created by the photons recombine, these photons are not utilized effectively. In this way, increasing the light intensity causes much more energy waste instead of much more degradation of VOCs consequently imposing unnecessary energy costs [64].

In this work, to evaluate the influence of light intensity on the degradation of acrylonitrile, experiments are performed with constant $\mathrm{C}_{0}$ and $\mathrm{v}$ at $2 \mathrm{ppm}$ and $1 \mathrm{~m} . \mathrm{s}^{-1}$ respectively whilst light intensities are varied in the range of $1-4.5 \mathrm{~mW} . \mathrm{cm}^{-2}$.

Fig. 5 shows the influence of the light intensity on the $\alpha$ during acrylonitrile degradation. The initial concentration and velocity were fixed at $2 \mathrm{ppm}$ and $1 \mathrm{~m} . \mathrm{s}^{-1}$ respectively. From the graph, it can be seen that the $\alpha$ increases from 0.005 to 0.12 when the light intensity increases from 1 to $4.5 \mathrm{~mW} . \mathrm{cm}^{-2}$.

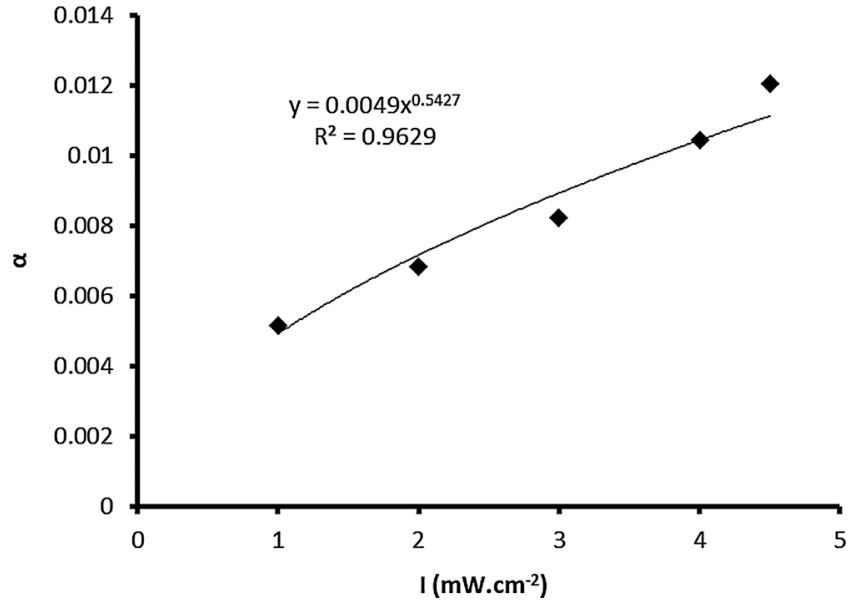

Fig. 5. Effect of light intensity the single pass removal efficiency determined during acrylonitrile degradation under experimental conditions of $\mathrm{C}_{0}=2 \mathrm{ppm}$ and $\mathrm{v}=1 \mathrm{~m} \cdot \mathrm{s}^{-1} ; \mathrm{RH}=50 \%$.

The relationship between $\alpha$ and light intensity was well described by a power function and was non-linear. The power exponent was calculated as 0.5. This result is similar to what Raillard et al. [49] reported when they studied the degradation of toluene in a closed loop reactor at similar light intensities of $1-4 \mathrm{~mW} . \mathrm{cm}^{-2}$. This half-order relationship indicates that over the range of light intensities studied, the reactions were dominated by the electron-hole recombination effect. As previously mentioned, the efficiency increases with the light intensity since more hydroxyl radicals are generated. However, the recombination of the electron-hole pairs at high light intensity inhibits the rate of electron transfer and thus increasing the light intensity would not significantly improve or influence the removal efficiencies but would only impose unnecessary energy costs.

According to our results, for the range of light intensities studied, higher light intensities provide better degradation performance better removal efficiencies for acrylonitrile. However, due to reduction in quantum efficiency as a result of the domination of electron-hole recombination, increasing the light intensity above $5 \mathrm{~mW} . \mathrm{cm}^{-2}$ would not significantly improve the removal efficiencies but would only impose unnecessary energy costs.

\subsection{Effect of initial concentration on the single-pass removal efficiency during photocatalytic degradation of acrylonitrile}

From literature, the pollutant initial concentration plays an important role on the performance of photocatalytic oxidation. For various classes and concentration ranges of VOCs, higher concentrations generally result in lower removal efficiencies $[53,65]$. This can be explained from two perspectives. Firstly, due to the fixed active sites on the photocatalytic media surface the amount of molecules effectively participating in the photocatalytic reaction is not enhanced in the same ratio as an increase of the inlet concentration resulting in a decrease of removal efficiency $[53,66]$. Secondly, there could be the interference of intermediates as higher amounts of intermediates generated during PCO reactions could occupy part of the active sites and impede the degradation progress $[67,68]$. Zhong et al. [68] studied the degradation of eight VOCs using a media made up of $\mathrm{TiO}_{2}$ coated on fiber glass fibers placed in a open-loop PCO reactor. They found that the removal efficiency of all eight VOCs decreased when the initial concentrations were increased from 0.25 to $1 \mathrm{ppm}$. They attributed this behavior to the fixed active sites at the catalyst surface. The amount of active sites compared to pollutant molecules decreases and consequently the removal efficiency is decreased.

The concentration of the pollutants in the OR varies depending on the activities performed and could range from several ppb to some tens 


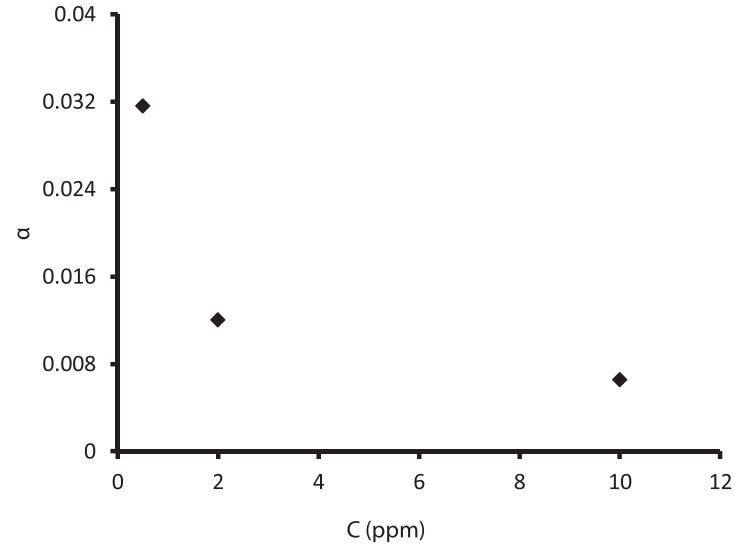

Fig. 6. Effect of initial concentration on the single pass removal efficiency determined during acrylonitrile degradation $\left(\mathrm{v}=1 \mathrm{~m} . \mathrm{s}^{-1} ; \mathrm{I}=4.5 \mathrm{~mW} . \mathrm{cm}^{-2}\right.$; $\mathrm{RH}=50 \%)$.

of ppm. For this reason, the initial concentrations of acrylonitrile were therefore studied from 0.5 to $10 \mathrm{ppm}$. This would provide some knowledge on the performance of PCO in degrading these compounds under possible $\mathrm{OR}$ concentrations. The air velocity $\mathrm{v}$ and light intensity I were kept constant at $1 \mathrm{~m} . \mathrm{s}^{-1}$ and $4.5 \mathrm{~mW} . \mathrm{cm}^{-2}$ respectively. Fig. 6 shows the effect of the initial concentration on $\alpha$.

It can be observed that the single-pass removal efficiencies decreased from 0.032 to 0.0066 when the concentration is increased. Due to the limited number of active sites on the media, an increase in concentration leads to competition between molecules for chance to be adsorbed onto the active sites and degraded. As the number of active sites is fixed, more molecules leave the media without undergoing degradation. This is in accordance with what Jafarikojour et al. [69] observed for toluene degradation at concentration range of 20 to 100 ppm and with Kricheevskaya et al. [42] who also noticed a decline in the removal efficiencies during acrylonitrile degradation from 10 to $100 \mathrm{ppm}$.

\subsection{Mineralization rates obtained during the degradation of acrylonitrile}

In order to completely characterize the performance of PCO it is necessary to also determine the mineralization rates. This is done by measuring the amounts of $\mathrm{CO}_{2}$ produced and comparing this value to the amount of $\mathrm{CO}_{2}$ which is expected to be produced when there is complete mineralization. The mineralization rates were studied by looking at the influence at different initial concentrations. The conversion rates were calculated as:

Conversion rate $=\frac{\boldsymbol{C}_{0}-\boldsymbol{C}_{\boldsymbol{t}}}{\boldsymbol{C}_{0}}$

where $C_{o}$ is the initial concentration and $C_{t}$ is concentration at time $t$.

The mineralization rate (\%) was determined by comparing the concentration of $\mathrm{CO}_{2}$ produced to the theoretical one (if mineralization is complete: $1 \mathrm{~mol}$ of acrylonitrile should lead to the formation of $3 \mathrm{~mol}$ of $\mathrm{CO}_{2}$ ), using the following equation:

Mineralization rate $(\%)=\frac{\left[\mathrm{CO}_{2}\right]}{\left[\text { theoretical } \mathrm{CO}_{2}\right]} \boldsymbol{x} 100$

where

$[$ theoretical CO2] $=3 \boldsymbol{x}$ [measured inlet acrylonitrile $]$

Figs. 7-9 show the evolution of the mineralization rate and the conversion rate for different acrylonitrile concentrations.

For all three studied concentrations: (i) $\mathrm{CO}_{2}$ was formed from the beginning of the degradation and it increased until a stable value (ii) $100 \%$ mineralization was achieved. All the eventual organic

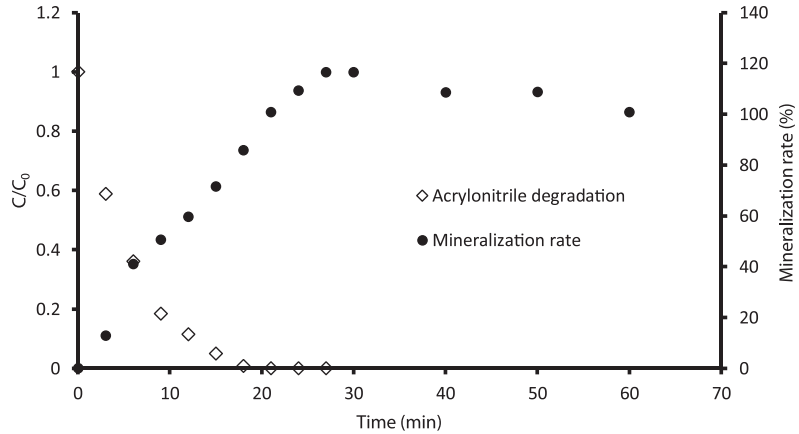

Fig. 7. Evolution of pollutant conversion and $\mathrm{CO}_{2}$ mineralization rate during the photocatalytic oxidation of acrylonitrile $\left(\mathrm{C}_{0}=0.5 \mathrm{ppm} ; \mathrm{v}=1 \mathrm{~m} . \mathrm{s}^{-1}\right.$; I $=4.5 \mathrm{~mW} \cdot \mathrm{cm}^{-2} ; \mathrm{RH}=50 \%$ ).

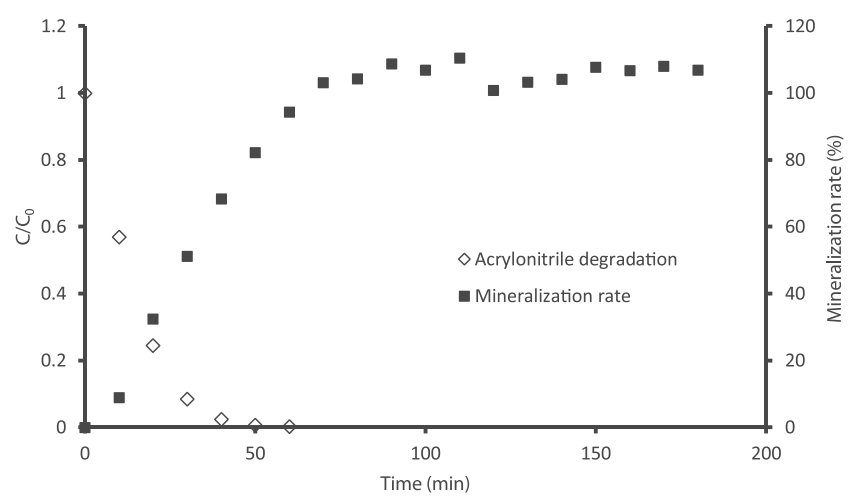

Fig. 8. Evolution of conversion and $\mathrm{CO}_{2}$ mineralization rate during the photocatalytic oxidation of acrylonitrile $\left(\mathrm{C}_{0}=2 \mathrm{ppm} ; \mathrm{v}=1 \mathrm{~m} . \mathrm{s}^{-1} ; \mathrm{I}=4.5 \mathrm{~mW} . \mathrm{cm}^{-}\right.$ ; $\mathrm{RH}=50 \%)$.

intermediates are adsorbed and oxidized into $\mathrm{CO}_{2}$.

In the case of initial concentration of $0.5 \mathrm{ppm}$ and $2 \mathrm{ppm}, 100 \%$ mineralization was achieved almost instantaneously to $100 \%$ conversion. For $0.5 \mathrm{ppm}, 100 \%$ conversion was achieved at around $18 \mathrm{~min}$ whilst $100 \%$ was achieved at around $23 \mathrm{~min}$. For $2 \mathrm{ppm} 100 \%$ conversion is achieved in about $60 \mathrm{~min}$ whilst complete degradation is achieved in about $70 \mathrm{~min}$. However, for $10 \mathrm{ppm}$, at $100 \%$ conversion of acrylonitrile about $70 \%$ of the organic compounds had been transformed to $\mathrm{CO}_{2}$. Then about $120 \mathrm{~min}$ after total removal of acrylonitrile from the gas phase, $100 \%$ mineralization was achieved. This delay could possibly be attributed to the fact that at higher concentration of $10 \mathrm{ppm}$, higher concentrations of intermediates were formed which would require more time to be mineralized. A two step mineralization rate was also observed (Fig. 10), with the first step involving the fast transformation of acrylonitrile into organic intermediate compounds which were also quickly transformed into $\mathrm{CO}_{2}\left(0.008 \mathrm{ppm} \mathrm{min}{ }^{-1}\right)$ followed by a slower mineralization $\left(0.003 \mathrm{ppm} \mathrm{min}^{-1}\right)$ of more stable intermediates into $\mathrm{CO}_{2}$.

To study the promptness of conversion of a compound and its reaction intermediates to $\mathrm{CO}_{2}$, Debono et al. [70] suggested that the mineralization rates be plotted as a function of the conversion rates. The results are acrylonitrile conversion rate vs mineralization rates for the three concentrations studied are shown in Fig. 10.

The dashed line represents the instantaneous conversion of the target compound into $\mathrm{CO}_{2}$. Consequently, if acrylonitrile was instantaneously converted in $\mathrm{CO}_{2}$ the plotted data would fit the dotted line. For all three concentrations, the results show a gap between the dotted line and the plotted data. It can also be observed that the mineralization rate at the beginning is low compared to the conversion rate but it increases until the total conversion of acrylonitrile. This gap corresponds to the fact that photocatalytic degradation of acrylonitrile 


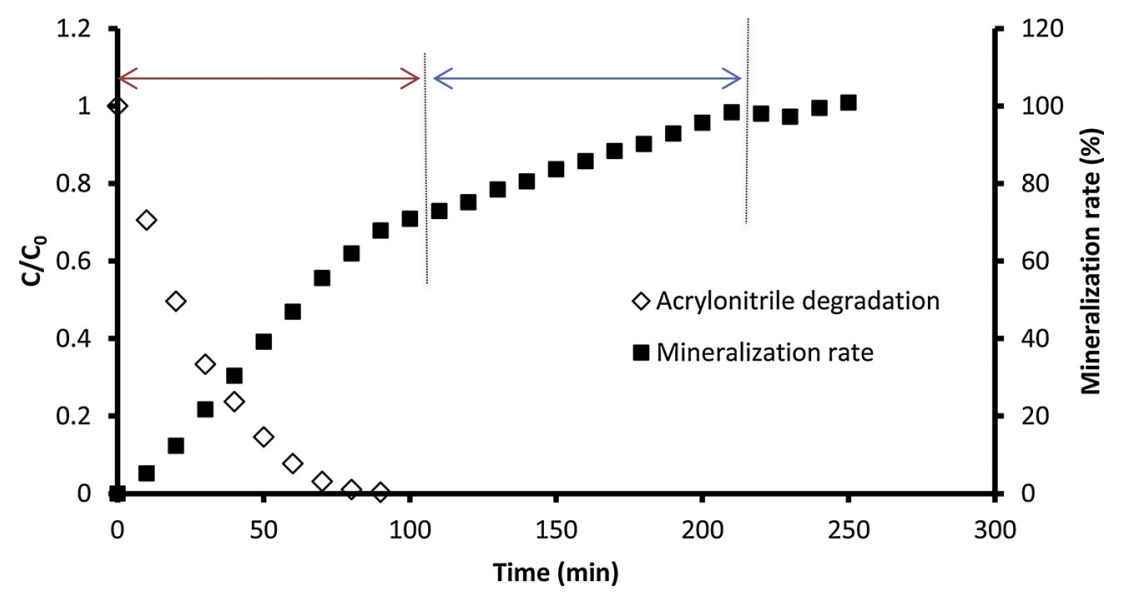

Fig. 9. Evolution of conversion and $\mathrm{CO}_{2}$ mineralization rate during the photocatalytic oxidation of acrylonitrile $\left(\mathrm{C}_{0}=10 \mathrm{ppm} ; \mathrm{v}=1 \mathrm{~m} . \mathrm{s}^{-1} ; \mathrm{I}=4.5 \mathrm{~mW} . \mathrm{cm}^{-2}\right.$; $\mathrm{RH}=50 \%)$.

involves the transient formation of reaction intermediates.

Conclusively, even though $100 \%$ mineralization is reached at around $100 \%$ removal for $0.5 \mathrm{ppm}$ and $2 \mathrm{ppm}$, acrylonitrile is not immediately converted to $\mathrm{CO}_{2}$ but first into intermediate compounds.

In this study, no intermediate compound was detected during the degradation of acrylonitrile. However, when Krichevskaya et al. [42] studied the degradation of acrylonitrile inlet concentrations of $40 \mathrm{ppm}$ in annular reactor, they identified carbon dioxide, water and nitrogen dioxide as the main products. They also noticed the formation of hydrogen cyanide, a compound classified by the US EPA as an extremely toxic compound. The inability to detect intermediates including

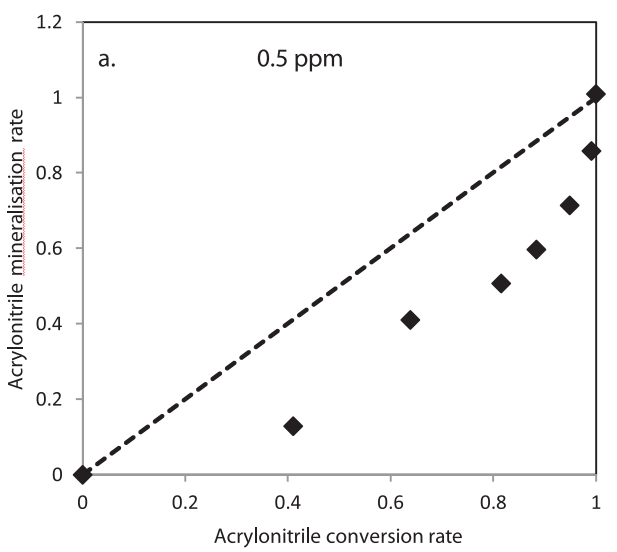

hydrogen cyanide in this study could be explained by the fact that the analytical methods were probably not adapted for this or that intermediates were at very low concentrations.

\section{Conclusion}

In this work, acrylonitrile which is a pollutant found in surgical smoke is degraded in a closed loop laboratory reactor to evaluate the efficiency of degradation by PCO. The use of a model developed by Dumont and Héquet enables the calculation of the single pass removal efficiency, the qualitative descriptor that allows the study of the

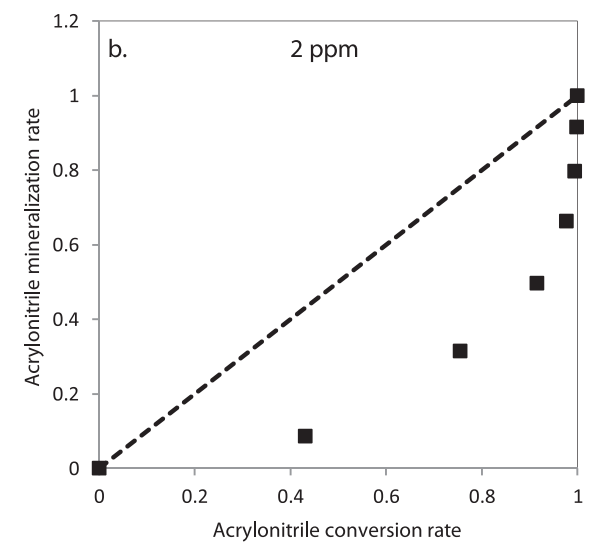

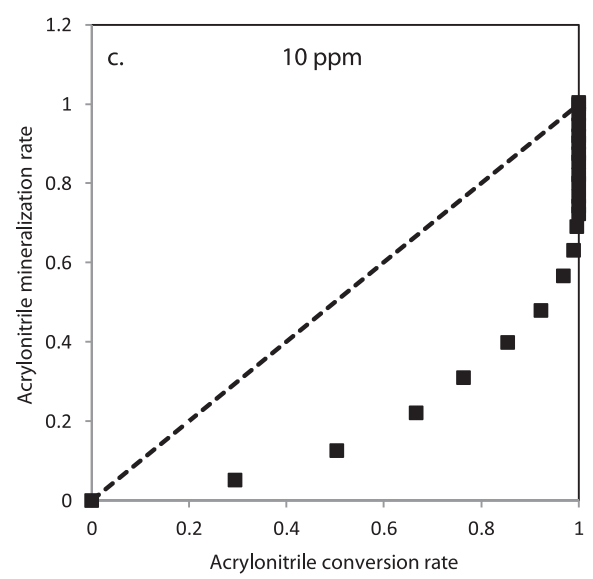

Fig. 10. Evolution of mineralization rates as a function of conversion rates during the photocatalytic oxidation of acrylonitrile at initial concentrations of (a) $0.5 \mathrm{ppm}$ (b) $2 \mathrm{ppm}$ and (c) $10 \mathrm{ppm}\left(\mathrm{v}=1 \mathrm{~m} \cdot \mathrm{s}^{-1}\right.$; I $=4.5 \mathrm{~mW} \cdot \mathrm{cm}^{-2}$; $\left.\mathrm{RH}=50 \%\right)$. 
influence of the air velocity, light intensity and initial concentration on the degradation process.

The results showed that PCO is able to degrade acrylonitrile. Decreasing the air velocity resulted in improved single-pass removal efficiencies due to higher contact time between the molecules and the photocatalytic media. Higher single-pass removal efficiencies were achieved at higher average light intensities. The relationship between light intensity and removal efficiency was seen to follow a half-order regime. This meant that for the range of light intensities studied the electron-hole recombination was dominant. In this case, further increment in the light intensity would not significantly improve the removal efficiencies but would only impose unnecessary energy costs. Higher initial concentrations of acrylonitrile led to a decrease in their degradation efficiencies attributed to limited active sites. However, due to the fact that the concentrations of pollutants vary over time, the use of multiple photocatalytic banks would help to maximize the removal efficiencies of pollutants. This would also be beneficial in reducing concentrations of intermediates and keeping them at levels that would not pose health risks.

In this work, the absence of intermediates such as hydrogen cyanide that was observed by Krichevskaya et al. [42] does not rule out their existence. Indeed by plotting the mineralization rates as a function of the conversion rates it was shown that during the course of degradation, acrylonitrile was first converted into organic intermediate compounds which were then converted into $\mathrm{CO}_{2}$. Further analysis using different and possibly more sensitive methods are recommended as these could help to identify anticipated and additional intermediates.

\section{Acknowledgements}

The authors would like to express their gratitude to ATA Medical and IMT Atlantique for their financial support and also to Eric Chevrel, Patrick Brion, Francois-Xavier Blanchet, Yvan Gouriou and Katell Chaillou for their invaluable technical assistance and Eric Dumont for his help with the modeling.

\section{References}

[1] J. Sundell, H. Levin, W.W. Nazaroff, W.S. Cain, W.J. Fisk, D.T. Grimsrud, F. Gyntelberg, Y. Li, A.K. Persily, A.C. Pickering, J.M. Samet, J.D. Spengler, S.T. Taylor, C.J. Weschler, Ventilation rates and health: multidisciplinary review of the scientific literature, Indoor Air 21 (2011) 191-204, https://doi.org/10.1111/j. 1600-0668.2010.00703.x.

[2] M.P. Bivolarova, A.K. Melikov, C. Mizutani, K. Kajiwara, Z.D. Bolashikov, Bed-integrated local exhaust ventilation system combined with local air cleaning for improved IAQ in hospital patient rooms, Build. Environ. 100 (2016) 10-18, https:// doi.org/10.1016/J.BUILDENV.2016.02.006.

[3] C.-C. Jung, P.-C. Wu, C.-H. Tseng, H.-J. Su, Indoor air quality varies with ventilation types and working areas in hospitals, Build. Environ. 85 (2015) 190-195 (accessed December 19, 2017), http://www.sciencedirect.com/science/article/pii/ S0360132314003989?via\%3Dihub.

[4] U.-M. Hellgren, P. Eero, M. Lahtinen, R. Henri, K. Reijula, Complaints and symptoms among hospital staff in relation to indoor air and the condition and need for repairs in hospital buildings, SJWEH Suppl (2008).

[5] V. Bessonneau, L. Mosqueron, A. Berrubé, G. Mukensturm, S. Buffet-Bataillon, J.P. Gangneux, O. Thomas, VOC contamination in hospital, from stationary sampling of a large panel of compounds, in view of healthcare workers and patients exposure assessment, PLoS One 8 (2013), https://doi.org/10.1371/journal.pone.0055535.

[6] M. Leung, A.H.S. Chan, Control and management of hospital indoor air quality, Med. Sci. Monit. 12 (2006) SR17-23 (Accessed 20 March 2017), http://www.ncbi. nlm.nih.gov/pubmed/16501436.

[7] J.P. Gangneux, S. Belaz, G. Barbe, O. Blanchard, F. Mercier, P.Y. Donnio, M. Guillaso, A. Rivier, P. Le Can, A. Florentin, E. Baures, Concomitant determination of indoor air microbiological and chemical contamination for a global approach of air quality in hospitals, Mycoses 60 (2017) 122-123.

[8] E.G. Dascalaki, A. Lagoudi, C.A. Balaras, A.G. Gaglia, Air quality in hospital operating rooms, Build. Environ. 43 (2008) 1945-1952, https://doi.org/10.1016/j. buildenv. 2007.11.015.

[9] C.A. Balaras, E. Dascalaki, A. Gaglia, HVAC and indoor thermal conditions in hospital operating rooms, Energy Build. 39 (2007) 454-470, https://doi.org/10. 1016/j.enbuild.2006.09.004.

[10] W.L. Barrett, S.M. Garber, Surgical smoke: a review of the literature, Surg. Endosc. Other Interv. Tech. 17 (2003) 979-987, https://doi.org/10.1007/s00464-0028584-5.
[11] E. Alp, D. Bijl, R.P. Bleichrodt, B. Hansson, A. Voss, Surgical smoke and infection control, J. Hosp. Infect. 62 (2006) 1-5, https://doi.org/10.1016/j.jhin.2005.01. 014.

[12] J.K.-M. Fan, F.S.-Y. Chan, K.-M. Chu, Surgical smoke, Asian J. Surg. 32 (2009) 253-257, https://doi.org/10.1016/S1015-9584(09)60403-6.

[13] D.S. Hill, J.K. O'Neill, R.J. Powell, D.W. Oliver, Surgical smoke - a health hazard in the operating theatre: a study to quantify exposure and a survey of the use of smoke extractor systems in UK plastic surgery units, J. Plast. Reconstr. Aesthet. Surg. 65 (2012) 911-916, https://doi.org/10.1016/J.BJPS.2012.02.012.

[14] O.S. Al Sahaf, I. Vega-Carrascal, F.O. Cunningham, J.P. McGrath, F.J. Bloomfield, Chemical composition of smoke produced by high-frequency electrosurgery, Ir. J. Med. Sci. 176 (2007) 229-232, https://doi.org/10.1007/s11845-007-0068-0.

[15] IARC, IARC Monographs on the Evaluation of carcinogenic risks to humans Classifications, http://monographs.iarc.fr/ENG/Classification/ (n.d.) (Accessed 29 April 2018).

[16] D.S. Hill, J.K. O'Neill, R.J. Powell, D.W. Oliver, Surgical smoke - a health hazard in the operating theatre: a study to quantify exposure and a survey of the use of smoke extractor systems in UK plastic surgery units, J. Plast. Reconstr. Aesthetic Surg. JPRAS 65 (2012) 911-916, https://doi.org/10.1016/j.bjps.2012.02.012.

[17] N. Mowbray, J. Ansell, N. Warren, P. Wall, J. Torkington, Is surgical smoke harmful to theater staff? A systematic review, Surg. Endosc. 27 (2013) 3100-3107, https:// doi.org/10.1007/s00464-013-2940-5.

[18] Y.J. Chung, S.K. Lee, S.H. Han, C. Zhao, M.K. Kim, S.C. Park, J.K. Park, Harmful gases including carcinogens produced during transurethral resection of the prostate and vaporization, Int. J. Urol. 17 (2010) 944-949, https://doi.org/10.1111/j.1442 2042.2010.02636.x.

[19] V. Bergeron, G. Reboux, J.L. Poirot, N. Laudinet, Decreasing airborne contamination levels in high-risk hospital areas using a novel mobile air-treatment unit, Infect. Control Hosp. Epidemiol. 28 (2007) 1181-1186, https://doi.org/10.1086/520733.

[20] T.S. Le, T.H. Dao, D.C. Nguyen, H.C. Nguyen, I.L. Balikhin, Air purification equipment combining a filter coated by silver nanoparticles with a nano-TiO 2 photocatalyst for use in hospitals, Adv. Nat. Sci. Nanosci. Nanotechnol. 6 (2015) 015016, , https://doi.org/10.1088/2043-6262/6/1/015016.

[21] M. Perraud, M.C. Nicolle, E. Chiarello, F. Tissot Guerraz, J.C. Cetre, M. Sepetjan, Air filtration and prevention of aspergillary pneumopathies. Preliminary comparative study of two mobile units for bacteriological air purification with recycling, Nouv. Rev. Fr. Hematol. 34 (1992) 295-299.

[22] R.A. Rosenbaum, J.S. Benyo, R.E. O'Connor, B.A. Passarello, D.R. Williams, B.D. Humphrey, R.W. Ross, J.M. Berry, J.G. Krebs, Use of a portable forced air system to convert existing hospital space into a mass casualty isolation area, Ann. Emerg. Med. 44 (2004) 628-634, https://doi.org/10.1016/j.annemergmed.2004. 03.012 .

[23] T. Schoenleber, H. Gbaguidi Haore, L. Jeunet, D. Talon, Évaluation d'un dispositif mobile de décontamination pour la maîtrise de l'air au bloc opératoire, Hygienes 15 (2007) 158-164.

[24] Center for Disease Control and Prevention, Guidelines for Environmental Infection Control in Health-Care Facilities: Recommendations of CDC and the Healthcare Infection Control Practices Advisory Committee (HICPAC), (2013).

[25] Société Franciase d'Hygiène Hospitalière, Qualité de l'air au bloc opératoire et autres secteurs interventionnels, (2015).

[26] H. Destaillats, M. Sleiman, D.P. Sullivan, C. Jacquiod, J. Sablayrolles, L. Molins, Key parameters influencing the performance of photocatalytic oxidation (PCO) air purification under realistic indoor conditions, Appl. Catal. B Environ. 128 (2012) 159-170, https://doi.org/10.1016/j.apcatb.2012.03.014.

[27] Y. Boyjoo, H. Sun, J. Liu, V.K. Pareek, S. Wang, A review on photocatalysis for air treatment: From catalyst development to reactor design, Chem. Eng. J. 310 (2017) 537-559, https://doi.org/10.1016/J.CEJ.2016.06.090.

[28] H. Ren, P. Koshy, W.-F. Chen, S. Qi, C.C. Sorrell, Photocatalytic materials and technologies for air purification, J. Hazard. Mater. 325 (2017) 340-366, https:// doi.org/10.1016/j.jhazmat.2016.08.072.

[29] J. Mo, Y. Zhang, R. Yang, Novel insight into VOC removal performance of photocatalytic oxidation reactors, Indoor Air 15 (2005) 291-300, https://doi.org/10. 1111/j.1600-0668.2005.00374.x.

[30] J. Zhao, X. Yang, Photocatalytic oxidation for indoor air purification: a literature review, Build. Environ. 38 (2003) 645-654, https://doi.org/10.1016/S03601323(02)00212-3.

[31] J. Mo, Y. Zhang, Q. Xu, J.J. Lamson, R. Zhao, Photocatalytic purification of volatile organic compounds in indoor air: a literature review, Atmos. Environ. 43 (2009) 2229-2246.

[32] L. Zhong, F. Haghighat, Photocatalytic air cleaners and materials technologies Abilities and limitations, Build. Environ. 91 (2015) 191-203, https://doi.org/10 1016/J.BUILDENV.2015.01.033.

[33] C. Raillard, V. Héquet, P. Le Cloirec, J. Legrand, Kinetic study of ketones photocatalytic oxidation in gas phase using TiO2-containing paper: effect of water vapor, J. Photochem. Photobiol. A Chem. 163 (2004) 425-431.

[34] M. Sleiman, P. Conchon, C. Ferronato, J.-M. Chovelon, Photocatalytic oxidation of toluene at indoor air levels (ppbv): towards a better assessment of conversion, reaction intermediates and mineralization, Appl. Catal. B Environ. 86 (2009) $159-165$

[35] C.H.H. Ao, S.C.C. Lee, J.Z.Z. Yu, J.H.H. Xu, Photodegradation of formaldehyde by photocatalyst TiO2: effects on the presences of NO, SO2 and VOCs, Appl. Catal. B Environ. 54 (2004) 41-50.

[36] X. Ye, D. Chen, J. Gossage, K. Li, Photocatalytic oxidation of aldehydes: byproduct identification and reaction pathway, J. Photochem. Photobiol. A: Chem. 183 (2006) 35-40, https://doi.org/10.1016/j.jphotochem.2006.02.019.

[37] W. Chen, J.J. Zhang, Photocatalytic oxidation of multi-component systems - an 
investigation using toluene/ethylbenzene, octane/decane/dodecane and formaldehyde/acetaldehyde, J. Adv. Oxid. Technol. 11 (2016) 163-173, https://doi. org/10.1515/jaots-2008-0123.

[38] Q.L. Yu, H.J.H. Brouwers, Indoor air purification using heterogeneous photocatalytic oxidation. Part I: experimental study, Appl. Catal. B Environ. 92 (2009) 454-461, https://doi.org/10.1016/j.apcatb.2009.09.004.

[39] V. Héquet, F. Batault, C. Raillard, F. Thévenet, L. Le Coq, E. Dumont, Determination of the Clean Air Delivery Rate (CADR) of Photocatalytic Oxidation (PCO) Purifiers for Indoor Air Pollutants Using a Closed-Loop Reactor. Part II: Experimental Results, Molecules 22 (2017), https://doi.org/10.3390/molecules22030408.

[40] Ü. Palmiste, H. Voll, Gas-phase optical fiber photocatalytic reactors for indoor air application: a preliminary study on performance indicators, IOP Conf. Ser. Mater. Sci. Eng. 251 (2017) 012055, , https://doi.org/10.1088/1757-899X/251/1/ 012055.

[41] J. Kolarik, P. Wargocki, Can a photocatalytic air purifier be used to improve the perceived air quality indoors? Indoor Air 20 (2010) 255-262, https://doi.org/10 1111/j.1600-0668.2010.00650.x.

[42] M. Krichevskaya, S. Jõks, A. Kachina, S. Preis, Gas-phase photocatalytic oxidation of acrylonitrile, Photochem. Photobiol. Sci. 8 (2009) 600, https://doi.org/10.1039/ b817063k.

[43] S. Jõks, M. Krichevskaya, S. Preis, Gas-phase photocatalytic oxidation of acrylonitrile on sulphated TiO2: continuous flow and transient study, Catal. Lett. 141 (2011) 309-315, https://doi.org/10.1007/s10562-010-0501-2.

[44] D. Pang, Y. Wang, X. Ma, F. Ouyang, Fluorine promoted and silica supported TiO2 for photocatalytic decomposition of acrylonitrile under simulant solar light irradiation, Chem. Eng. J. 258 (2014) 43-50, https://doi.org/10.1016/J.CEJ.2014.07. 068.

[45] D. Pang, L. Qiu, Y. Wang, R. Zhu, F. Ouyang, Photocatalytic decomposition of acrylonitrile with $\mathrm{N}-\mathrm{F}$ codoped $\mathrm{TiO} 2 / \mathrm{SiO} 2$ under simulant solar light irradiation, J. Environ. Sci. 33 (2015) 169-178, https://doi.org/10.1016/J.JES.2015.01.017.

[46] E. Dumont, V. Héquet, Determination of the clean air delivery rate (CADR) of photocatalytic oxidation (PCO) purifiers for indoor air pollutants using a closedloop reactor. Part I: theoretical considerations, Molecules 22 (2017), https://doi org/10.3390/molecules22030407.

[47] V. Héquet, C. Raillard, O. Debono, F. Thévenet, N. Locoge, L. Le Coq, Photocatalytic oxidation of VOCs at ppb level using a closed-loop reactor: the mixture effect, Appl. Catal. B Environ. (2017), https://doi.org/10.1016/j.apcatb.2017.12.041.

[48] F. Batault, V. Héquet, C. Raillard, F. Thévenet, N. Locoge, L. Le Coq, How chemical and physical mechanisms enable the influence of the operating conditions in a photocatalytic indoor air treatment device to be modeled, Chem. Eng. J. 307 (2017) 766-775, https://doi.org/10.1016/j.cej.2016.08.118.

[49] C. Raillard, A. Maudhuit, V. Héquet, L. Le Coq, J. Sablayrolles, L. Molins, Use of experimental designs to establish a kinetic law for a gas phase photocatalytic process, Int. J. Chem. React. Eng. 12 (2014) 113, https://doi.org/10.1515/ijcre-20140012 .

[50] A. Maudhuit, C. Raillard, V. Héquet, L. Le Coq, J. Sablayrolles, L. Molins, Adsorption phenomena in photocatalytic reactions: the case of toluene, acetone and heptane, Chem. Eng. J. 170 (2011) 464-470, https://doi.org/10.1016/j.cej.2011. 02.040 .

[51] H.E. Whyte, C. Raillard, A. Subrenat, V. Hequet, Photocatalytic oxidation of isoflurane, an anesthetic gas: the influence of operating parameters, Chem. Eng. J. (2018), https://doi.org/10.1016/j.cej.2018.07.059.

[52] A.T.S. Walker, A.A. Wragg, The modelling of concentration-time relationships in recirculating electrochemical reactor systems, Electrochim. Acta 22 (1977) 1129-1134, https://doi.org/10.1016/0013-4686(77)80051-0.

[53] A.H. Mamaghani, F. Haghighat, C.-S.S. Lee, Photocatalytic oxidation technology for indoor environment air purification: the state-of-the-art, Appl. Catal. B Environ. 203
(2017) 247-269, https://doi.org/10.1016/J.APCATB.2016.10.037.

[54] K.-H. Wang, H.-H. Tsai, Y.-H. Hsieh, The kinetics of photocatalytic degradation of trichloroethylene in gas phase over TiO2 supported on glass bead, Appl. Catal. B Environ. 17 (1998) 313-320, https://doi.org/10.1016/S0926-3373(97)00099-4.

[55] H. Yu, K. Zhang, C. Rossi, Experimental study of the photocatalytic degradation of formaldehyde in indoor air using a nano-particulate titanium dioxide photocatalyst, Indoor Built Environ. 16 (2007) 529-537, https://doi.org/10.1177/ 1420326 X07083513.

[56] N. Quici, M.L. Vera, H. Choi, G.L. Puma, D.D. Dionysiou, M.I. Litter, H. Destaillats, Effect of key parameters on the photocatalytic oxidation of toluene at low concentrations in air under $254+185 \mathrm{~nm}$ UV irradiation, Appl. Catal. B Environ. 95 (2010) 312-319, https://doi.org/10.1016/j.apcatb.2010.01.009.

[57] L. Zhong, F. Haghighat, P. Blondeau, J. Kozinski, Modeling and physical interpretation of photocatalytic oxidation efficiency in indoor air applications, Build. Environ. 45 (2010) 2689-2697.

[58] L. Yang, A. Cai, C. Luo, Z. Liu, W. Shangguan, T. Xi, Performance analysis of a nove TiO2-coated foam-nickel PCO air purifier in HVAC systems, Sep. Purif. Technol. 68 (2009) 232-237, https://doi.org/10.1016/J.SEPPUR.2009.05.008.

[59] T.N. Obee, Photooxidation of sub-parts-per-million toluene and formaldehyde levels on titania using a glass-plate reactor, Environ. Sci. Technol. 30 (1996) 3578-3584, https://doi.org/10.1021/es9602713.

[60] A. Ginestet, D. Pugnet, J. Rowley, K. Bull, H. Yeomans, Development of a new photocatalytic oxidation air filter for aircraft cabin, Indoor Air 15 (2005) 326-334, https://doi.org/10.1111/j.1600-0668.2005.00369.x.

[61] J.-M. Herrmann, Heterogeneous photocatalysis: state of the art and present applications, Top. Catal. 34 (2005) 49-65, https://doi.org/10.1007/s11244-005-3788-2.

[62] D.F. Ollis, E. Pelizzetti, N. Serpone, Photocatalyzed destruction of water contaminants, Environ. Sci. Technol. 25 (1991) 1522-1529, https://doi.org/10.1021/ es00021a001.

[63] T.-H. Lim, S.-D. Kim, Photocatalytic degradation of trichloroethylene over TiO2/ SiO2 in an annulus fluidized bed reactor, Korean J. Chem. Eng. 19 (2002) 1072-1077, https://doi.org/10.1007/BF02707235.

[64] W. Wang, Y. Ku, Photocatalytic degradation of gaseous benzene in air streams by using an optical fiber photoreactor, J. Photochem. Photobiol. A: Chem. 159 (2003) 47-59, https://doi.org/10.1016/S1010-6030(03)00111-4.

[65] J. Mo, Y. Zhang, Q. Xu, R. Yang, Effect of TiO2/adsorbent hybrid photocatalysts for toluene decomposition in gas phase, J. Hazard. Mater. 168 (2009) 276-281, https://doi.org/10.1016/J.JHAZMAT.2009.02.033.

[66] F.V.S.S. Lopes, R.A.R.R. Monteiro, A.M.T.T. Silva, G.V. Silva, J.L. Faria, A.M. Mendes, V.J.P.P. Vilar, R.A.R.R. Boaventura, Insights into UV-TiO2 photocatalytic degradation of PCE for air decontamination systems, Chem. Eng. J. (2012) 244-257.

[67] A.H. Mamaghani, F. Haghighat, C.-S. Lee, Photocatalytic degradation of VOCs on various commercial titanium dioxides: impact of operating parameters on removal efficiency and by-products generation, Build. Environ. (2018), https://doi.org/10. 1016/j.buildenv.2018.05.002.

[68] L. Zhong, F. Haghighat, C.-S. Lee, N. Lakdawala, Performance of ultraviolet photocatalytic oxidation for indoor air applications: systematic experimental evaluation, J. Hazard. Mater. 261 (2013) 130-138.

[69] M. Jafarikojour, M. Sohrabi, S.J. Royaee, A. Hassanvand, Evaluation and optimization of a novel immobilized photoreactor for the degradation of gaseous toluene, CLEAN - Soil Air Water 43 (2015) 662-670, https://doi.org/10.1002/clen. 201300985.

[70] O. Debono, V. Héquet, L. Le Coq, N. Locoge, F. Thévenet, VOC ternary mixture effect on ppb level photocatalytic oxidation: removal kinetic, reaction intermediates and mineralization, Appl. Catal. B Environ. 218 (2017) 359-369, https://doi.org/ 10.1016/j.apcatb.2017.06.070 